ISSN : 2087-2461

PENANGGUNG JAWAB

Dekan FIKOM

Evie Sofiati MI, M.I.Kom

Sekretaris Dekan

Dian Marhaeni K, M.Si

Ketua Penyunting

Made Dwi Adnjani, M.Si

Sekretaris

Mubarok, M.Si

Bendahara

Parwati, SH

Dewan Penyunting

Trimanah, M.Si

Edi Ismoyo, M.Si

Suharyoso, S.Sos

Seksi Usaha

Endang Winarsih, S.Sos

Sirkulasi dan Distribusi

Novi, S.Sos

Alamat Redaksi

Fakultas Ilmu Komunikasi

Universitas Islam

Sultan Agung Semarang

Jl. Raya Kaligawe Km. 4

Po. Box 1054/SM

Semarang 50112

Telp. (024) 6583584

ext. $448 / 449$

Fax. (024) 6582455

email : jurnalfikom@yahoo.com
Pergeseran Makna Motif Batik Yogyakarta - Surakarta

Doddy Wihardi

Email:made_doddywihardi@yahoo.com

Riyodina G.Pratikto

Email:dinapratikto@yahoo.com

Shinta Kristanty

Email:shintasoultan@yahoo.com

Diskursus Cyberbullying Florence Sihombing

(Analisis Wacana Kritis Teun A. Van Dijk

Tentang Florence Sihombing di Dunia Maya)

Syntia Balina Dewi

syntiabalinadewi@gmail.com

Syarif Maulana

syarafmaulini@gmail.com

Kajian Interaksi Simbolik Pola Komunikasi

Etnis Arab dan Etnis Sunda Dalam Perkawinan Mut'ah

di Kecamatan Pacet Kabupaten Cianjur

Yessi Sri Utami

yessikhansa@gmail.com

Tabloidisasi Pemberitaan Mengenai Pemilu Presiden 2014

Pada Program Berita "Headline News" Metro TV

Urip Mulyadi

oeripmulia@gmail.com

Relevansi Teori Agenda Setting

Dalam Dunia Tanpa Batas

Kharisma Nasionalita

k_nasionalita@yahoo.co.id

"Children Go Online" di Indonesia, Apa dan Bagaimana? Nurist Surayya

nurist.surayya@undip.ac.id 


\title{
Tabloidisasi Pemberitaan Mengenai Pemilu Presiden 2014 Pada Program Berita "Headline News" Metro TV
}

\author{
Urip Mulyadi \\ Mahasiswa Program Studi Magister Ilmu Komunikasi Universitas Diponegoro \\ oeripmulia@gmail.com
}

\begin{abstract}
Program berita terkait isu politik dalam negeri pun dibuat tak kalah dramatis. Menggunakan lagu sebagai ilustrasi, pengucapan yang mendayu-dayu terkesan sinis dan tendensius. Seperti halnya saat masa-masa kampanye Calon Presiden 2014 seperti ini, pemberitaan di televise dikemas sedemikian rupa hingga kita sebagai penonton terbawa dalam suasana pertarungan. Berita-berita penting yang menyangkut isu public sering dikemas dengan gaya tabloid (tabloidisasi) yang ringan dan dangkal seperti pada program "Headline News" Metro TV. Hadirnya tabloidisasi kemudian membuat batas-batas antara quality pressdengan popular press menjadi cair.Gambaran mengenai tabloidisasi ini bisa dijelaskan dengan melihat proporsi yang termasuk komponen tabloidisasi, yakni dalam tulisan ini penulis menggunakan 3 unsur (Personalisasi, Sensasionalisme, Trivialisasi). Hasil penelitian ini menunjukkan bahwa Metro TV melakukan tabloidisasi pada berita mengenai Pemilu Presiden 2014 dalam program berita Headline News. Melalui 3 komponen tabloidisasi yakni (1) Personalisasi yang ditunjukkan dengan orientasi pemilihan topik berita yang lebih bernilai personal dibandingkan publik, (2) Sensasionalisme, pemberitaan yang dengan sengaja disampaikan secara provokatif atau dimanipulasi untuk "memukau" atau menarik perhatian pemirsa, (3) Trivialisasi, Dengan menyajikan data-data yang unik namun tidak memiliki relevansinya dengan pemilihan umum presiden 2014.
\end{abstract}

\section{Kata Kunci: Berita Pilpres, Tabloidisasi, Media Televisi}

\begin{abstract}
News programs related to political issuesin the country is made no less dramatic. Usingsongsas an illustration, pronunciationwas impressed cynical and tendentious. As well, the presidential election campaignin 2014 held, the television news is packaged like this until weas an viewers carried away in the atmosphere of battle. The important news concerning the issue of public often packed with style tabloid (tabloidization) were mild and shallow like the program"Headline News" on MetroTV. The presence tabloidization then make the boundaries between thequality press with the popular press there is no limit. Overview of tabloidization can be explained by looking at the proportion of components, there are personalization, sensasionalism, and triviliasization. The result showed that Metro TV did tabloidization on the Headline news program news about the 2014 Presidential Election. (1) Personalization is indicated by the orientation of election news topics that are more personal valuable than public. (2) Sensasionalism, news delivered deliberately provocative or manipulated for "riveting" or attract the attention of viewers. (3) Trivialization, presenting unique data but has no relevance to the 2014 presidential elections.
\end{abstract}

Keywords : Election News, Tabloidization, Television

\section{Pendahuluan}

Jurnalisme televisi saat ini tampak didikte oleh pasar, sehingga pada praktiknya pola jurnalistiknya perlahan- lahan mengadopsi pola pemberitaan pada jurnalisme tabloid. Fenomena tabloidisasi berawal dari perubahan surat kabar ke dalam format tabloid. 
Perubahan surat kabar ke dalam format tabloid ini turut mengubah isi editorial serta tata letak halaman dan ukurannya. Sebagian surat kabar akhirnya menekankan pada hiburan dan berita yang dibiaskan ke dalam cerita human interest dengan headline yang besar, menggunakan lebih banyak gambar dan warna yang mencolok (Franklin 1997: 113). Hal ini menunjukkan adanya penurunan penggunaan jurnalisme tradisional dan meningkatnya bentuk-bentuk budaya populer yang dilakukan untuk meningkatkan daya saing dan korporatisasi pasar media.

Sepuluh hingga lima belas tahun yang lalu, misalnya. Penonton berita mengenal dan melihat presenter berita dengan penampilan formal, serta membacakan berita satu ke berita yang lain dengan bahasa yang serius dan baku, tanpa diselingi komentar. Begitu juga berita yang ditampilkan di televisi kala itu. Selalu lugas, dengan teknik editing yang simpel, tanpa ada background musik apalagi lagu yang mengiringinya.

Puluhan tahun setelah kebebasan pers dihirup oleh para pekerja media,publik pun bisa mencatat adanya perubahan dalam tampilan berita di televisi kita. Yang berkembang kemudian, pelan-pelan televisi berita mengadopsi gaya infotainmen (pers kuning- penulis) dalam penyajian beritanya (Wijaya, 2012: 103).

Program berita terkait isu politik dalam negeri pun dibuat tak kalah dramatis. Menggunakan lagu sebagai ilustrasi, pengucapan yang mendayu-dayu terkesan sinis dan tendensius. Untuk sebuah topik yang sedang panas, tidak jarang ditampilkan narasumber instan yang kadang tidak jelas kompetensinya. (Wijaya, 2012: 103).Pers populer juga sering diidentikkan dengan kualitas yang rendah. Maka, gejala tabloidisasi sebagai adopsi formulasi dan standar pers populer ke dalam quality press inilah yang perlu diberi perhatian lebih. Sebab, pada dasarnya quality press memiliki orientasi pada isu serius seperti politik, ekonomi, dan sosial yang menjadiurusan publik, sementara pers populer lebih menekankan pada aspek hiburan dan privat (Mooney, 2008: 9). Sehingga wajar bila hari ini kritik selalu diarahkan pada cara pemberitaan pada televisi kita.

Seperti halnya saat masa-masa kampanye Calon Presiden 2014 seperti ini, pemberitaan di televise dikemas sedemikian rupa hingga kita sebagai penonton terbawa dalam suasana pertarungan yang "panas". Terlebih hanya terdapat dua kubu Capres dan Cawapres (JokowiJK dan Prabowo-Hatta) yang akan bertarung dalam Pilpres 9 Juli 2014 mendatang. Sehingga aroma persaingan terlihat dan tersaji dihadapan public. Bahkan tidak sedikit masyarakat turut larut dalam suasana persaingan ini dengan ikut menjadi simpatisan salah satu capres. Dalam hal pemberitaan yang disajikan media terkadang kita sebagai penonton menganggap berita-berita tersebut tidak terlalu penting untuk disajikan, namun tetap ditayangkan oleh media. Seperti dalam berita yang ditampilkan oleh Metro TV yang berjudul "Kayuh Becak Jogja-Jakarta Dukung Jokowi-JK" yang tayang pada 16 Juni 2014. Seperti yang terlihat dalam gambar dibawah ini :

\section{Gambar 1. Potongan Berita Pemilu Presiden 2014}

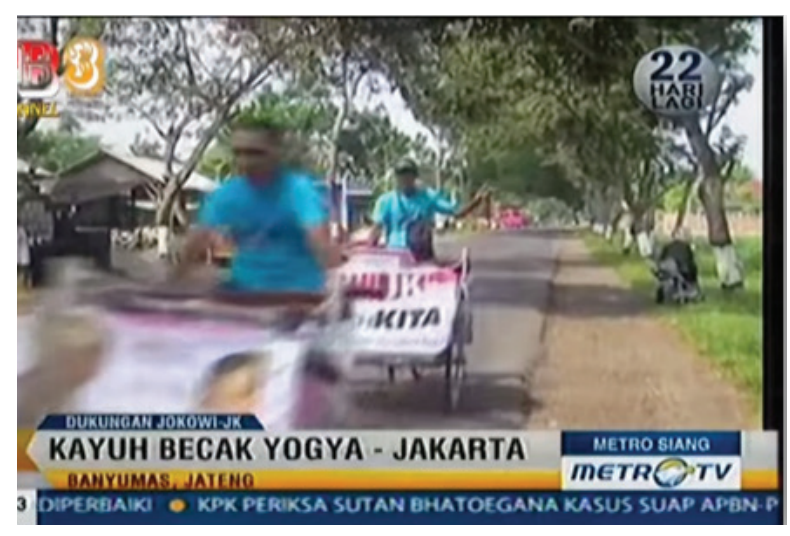

Sumber : Metro TV

Pemberitaan mengenai pemilu presiden 2014 ini mendapatkan porsi yang besar dalam program berita di televise, khususnya Metro TV. Hal ini pantas dipahami bahwa pemilihan umum merupakan peristiwa penting bagi negara demokrasi seperti Indonesia ini. "Pesta Demokrasi" yang digelar 5 tahun sekali ini merupakan sarana yang digunakan untuk menentukan pemimpin Indonesia dalam periode lima tahun kedepan. 
Maka dari itu Kajian tentang gejala tabloidisasi dalam program berita ini sendiri penting untuk dilakukan. Karena dalam masyarakat kontemporer saat ini, pesan dalam bentuk berita merupakan referensi bagi partisipasi individu dalam kegiatan politik, ekonomi, maupun kultural (Lozano, 2004:26). Persoalannya, selama ini audiens tidak ditempatkan sebagai warga negara, melainkan konsumen berita untuk mendapat rating yang tinggi. Akibatnya, berita-berita penting yang menyangkut isu public sering dikemas dengan gaya tabloid yang ringan dan dangkal. Jika demikian, audiens boleh jadi tidak mampu menerima informasi faktual yang berguna bagi pengambilan keputusannya sebagai seorang warga negara.

Sehingga dalam hal ini penulis hendak mengkaji gambran riil mengenai tabloidisasi dalam program berita televisi dengan melihat indikator-indikator tabloidisasi yang tampak pada pesan/isi berita. Namun mengingat banyaknya jumlah program berita yang ada, maka tulisan ini difokuskan untuk melihat pemberitaan mengenai pemilu presiden 2014 pada program "Headline News" Metro TV.Program berita ini tayang di jam prime time dan tulisan ini bukan untuk melihat bagaimana frame program berita ini dalam menyajikan berita Pemilu Presiden 2014 melainkan untuk melihat gambaran tabloidisasi yang terjadi. Bagaimana gambaran tabloidisasi yang muncul dalam pemberitaan mengenai Pemilu Presiden 2014 pada program berita "Headline News" Metro TV?

\section{Pembahasan}

Munculnya gaya baru jurnalisme, yang disebut McJournalism, mencerminkan dorongan untuk menerapkan efisiensi, kepastian, calculability, dan control melalui teknologi ini terbukti terjadi dalam pers local. Meskipun teori pasar mengklaim keragaman dan kualitas berita sebagai produk lebih penting dari kompetisi, kenyataannya McJournalism dan McPapers dengan berita yang hampir seragam dan sejumlah daya tarik lain dapat menarik pembaca.

Yellow journalism atau jurnalisme kuning identik dengan apa yang dikenal dengan isitilah tabloidisasi, yang diambil dari kata tabloid, sebuah produk media massa yang memprioritaskan lifestyle, hiburan, dan sensasi. Hal ini tidak terlepas karena tabloid merupakan salah satu produk nyata dari jurnalisme kuning dengan format yang berbeda dengan produk jurnalistik pada umumnya. Tabloid bisa dibilang sebagai produk jurnalisme populer yang kehadirannya menampilkan apayang tidak dapat dimuat pada jurnalisme mainstream. Jika jurnalisme populer biasa dijumpai dalam bentuk pers kuning seperti tabloid, jurnalisme mainstream secara konseptual termasuk dalam pers elit (quality/serious press) (Harrington, 2008: 5).

Maka, format berita televisi mesti diubah agar tidak membosankan dan mampu menggugah gairah untuk menonton. Hasilnya adalah berita-berita yang muncul di televisi lebih mengedepankan konflik dan drama atas sebuah peristiwa yang sering terlalu dilebihlebihkan. Selain itu, kualitas penyajian berita di televise seringkali lebih hanya menitikberatkan pada gambar, sementara unsur pelaporannya tidak kuat. Efek yang ditakutkan adalah ketika masyarakat justru terbiasa dengan jenis jurnalisme yang hanya akan memuaskan mereka, menghibur, namun tidak mendidik dan membangun kesadaran mereka.

Berita televisi sejatinya merupakan produk jurnalisme murni yang memiliki pakem tersendiri dan menyampaikan apa yang penting bagi khalayak. Namun, sejalan dengan logika bisnis, berita televisi kemudian hari beralih fungsi menjadi sebuah bentuk penayangan yang lebih condong menampilkan bentuk tabloidisasi untuk memenuhi "apa yang khalayak suka" dengan menurunkan standar jurnalistik yang dimiliki, menjadi standar tabloid yang dikenal sebagai terbitan yang meski faktual, tetapi lebih mengeksplor sisi hiburan.

Tabloid identik dengan gaya penyampaian berita yang sensasional, sedikit menitikberatkan pada kepentingan publik, justru seringkali menonjolkan aspek kehidupan pribadi ke ranah publik. Sebaliknya, pers non tabloid lebih menitikberatkan pada 
informasi publik dengan menggunakan cara penyampaian (bahasa) yang serius (McLachlan dan Golding dalam Sparks, 2000). Maka dari itu, secara konseptual, tabloid digolongkan ke dalam produk pers populer (popular press).

Topik yang juga rentan di-tabloidisasikan oleh televisi berita dalam hal ini Metro TV adalah pemilihan umum Presidem.Tampak berita seputar Pemilu Presiden 2014 menyita perhatian Metro TV, dengan kemunculan berita setiap harinya. Dalam program Headline News yang akan dikaji, penulis mencatat terdapat setidaknya 67 berita dalam program Headline News pada rentang waktu 16 hingga 28 Juni 2014, 35 diantaranya adalah berita mengenai pemilihan umum presiden 2014. Menarik untuk kemudian melihat bagaimana tabloidisasi terjadi pada berita seputar pemilihan umum Presiden 2014 tersebut. Pada masa pemilu, berita sudah pasti menjadi salah satu instrumen penting bagi warga. Tidak hanya untuk memberi informasi tentang siapa saja kandidat yang bersaing. Lebih penting dari itu, warga membutuhkan informasi yang memadai untuk menentukan pilihan.

Dalam konteks pemilihan umum, penonton akan menjadi lebih tahu siapa saja kandidat yang bisa dipilih, bahkan membawa mereka untuk mengetahui lebih dekat siapa para calon dan bagaimana program yang diusung.

Tetapi masalahnya adalah bagaimana berita-berita itu disampaikan? Apakah disiarkan dengan kedalaman informasi dan analisis, atau sekadar memberi tahu. Apakah dikemas dalam bentuk yang kontekstual, atau sekadar menyampaikan berita yang enak ditonton. Sebagai media massa yang beraliran "serius", televisi berita semestinya mampu menghadirkan berita dengan standar jurnalistik yang ketat. Standar ini umumnya merupakan representasi dari pers elit yang memberikan penekanan pada "rational and text-based, their counterparts play on the readers' emotions by using striking visuals, bold design, and colorful wording" (LehmanWilzig\&Seletzky, 2012: 2).

Problem muncul ketika praktik jurnalistik pada televisi berita MetroTV sebagai quality press, mengemas beritanya dengan gaya jurnalistik pers populer. Pola jurnalistik pers populer ini misalnya ditandai dengan "larger headline size, more pictures, and greater use of graphics" (LehmanWilzig\&Seletzky, 2012: 2).

Berita dalam "Headline News" MetroTV umumnya tidak menggunakan teks yang mendalam. Seperti contoh dalam berita yang berjudul "Prabowo Kampanye di Makassar, Tim Jokowi-JK bagikan Bunga Mawar dan Lepas Burung Dara" yang tayang pada 17 Juni 2014.

\section{Gambar 2. Potongan Berita Pemilu Presiden 2014}

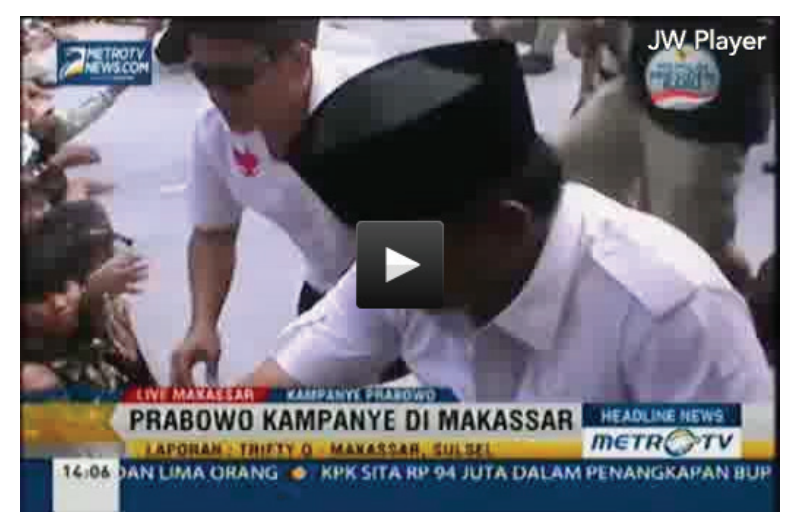

Sumber : Metro TV

Dengan Narasi :

Headline News, Selasa (17/6/2014): Calon presiden nomor urut satu Prabowo-Hatta berkampanye ke Makassar, Sulawesi Selatan. Usai berkampanye di Makassar, Prabowo akan mengunjungi Manado, Sulawesi Selatan. Sedangkan, tim Jokowi-JK menyambut dengan membagikan bunga mawar dan burung dara.

Sebagaimana telah dijelaskan sebelumnya, bahwa tabloidisasi disini dimaknai sebagai penurunan standar jurnalistik dari segi orientasinya terhadap nilai-nilai hiburan. Sehingga dimensi tabloidisasi yang hendak dicari disini bukan pada objektivitas. Melainkan aspek-aspek hiburan yang diaplikasikan dalam produk berita.Maka, dalam konteks pemberitaan Pilpres 2014, apa yang dicermati melalui seperangkat indikator tabloidisasi ini bukan mengacu 
pada objektivitas, keberpihakan, serta keberimbangan media yang terlihat melalui teks. Analisis terhadap ukuran tabloidisasi lebih dimaksudkanuntuk menunjukkan bahwa berita pemilu presiden disini mengandung dimensi hiburan, dan karenanya mengurangi kualitasinformasi yang diterima oleh publik selaku pemilih.

Maka, tabloidisasi dalam berita televisi coba dicari melalui keberadaan formula tabloidisasi yang diperoleh dari penelitian terdahulu, maupun konsep tabloidisasi yang telah ada.Dengan penyesuaian pada karakteristik datanya, maka dari itu dapat dirumuskan komponen tabloidisasi yang hendak dicari, diantaranya adalah Personalisasi, Sensaionalisme dan Trivialisasi.

\section{Personalisasi}

Ada dua pemahaman yang berbeda terhadap personalisasi dalam konteks kajian media. Pertama, personalisasi merupakan karakter dasar dalam produk hiburan. Dimana dalam setiap tayangan, unsur pertamanya adalah talent (person). Dalam berita, personalisasi berarti menempatkan isu person sebagai topik sentral. Dengan kata lain, pada sebuah peristiwa, isu yang ditonjolkan oleh media adalah orangnya, bukan substansi dari masalah itu sendiri. Dalam konteks politik, penggunaan personalisasi ini akan menjauhkan audiens dari persoalan publik (substansi), misalnya kebijakan, dan lebih terfokus pada citra (person). Tidak dapat disangkal bahwa ini merupakan sifat dasar dari televisi yang selalu membutuhkan gambar. Sedangkan topik seperti kebijakan itu abstrak. (Nusantari, 2013:46-47)

Selain itu, personalisasi merupakan karakter dasar dalam produk hiburan. Dimana dalam setiap tayangan, unsur pertamanya adalah talent (person). Dalam berita, personalisasi berarti menempatkan isu person sebagai topik sentral. Konsep personalisasi ini ditunjukkan seperti pada berita yang berjudul "Jokowi Minta Relawan Antisipasi Kecurangan Saat Pencoblosan" yang tayang pada 26 Juni 2014.
Gambar 3. Potongan Berita Pemilu Presiden 2014

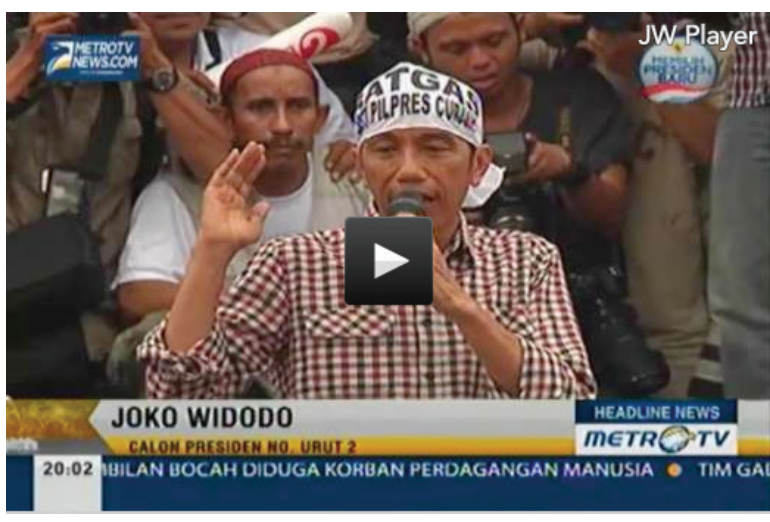

Sumber : Metro TV

Dengan Narasi :

Headline News, Kamis (26/6/2014): Calon Presiden nomor urut 2 Joko Widodo dalam acara Apel Satgas Relawan Jokowi-JK di Parkir Timur Senayan, Jakarta. Jokowi mengingatkan para relawan mengantisipasi segala macam kecurangan saat pencoblosan, serta mengamankan suara agar tidak terjadi manipulasi suara.

Berdasarkan kajian Rosa van Santen dan Liesbet van Zoonen (2011: 11-14), personalisasi bisa terjadi di wilayah institusi politik dan media. Di wilayah institusi, personalisasi terjadi ketika institusi seperti partai politik lebih memberi perhatian pada aktor politik mereka. Termasuk menjadikan pemimpin mereka sebagai ikon partai. Poin ini tidak akan dibahas dalam penelitian, karena tidak berada pada dimensi teks. Kedua adalah personalisasi yang dilakukan oleh media-yang menjadi salah satu elemen tabloidisasi yang akan diteliti dalam tulisan ini. Dalam kajian keduanya, personalisasi terjadi ketika media: (1) Lebih banyak memberitakan aktor politik ketimbang partai politik, (2) Lebih menyoroti kemampuan dan karakter individu seorang aktor politik, (3) Banyak memberitakan soal kehidupan pribadi politikus, (4) Berfokus pada emosi dan pengalaman pribadi dari seorang aktor politik.

Pandangan ini sejalan dengan Lozano (2004:6) yang menilaipersonalisasi dilakukan dengan memperlakukan berita 
politik sebagaimana berita hiburan atau kompetisi olahraga (horse race) yang lebih mengutamakan emosi, bukan pada substansi. Seperti yang ditunjukkan pada berita yang berjudul "Malam Hari, Jokowi Silaturahmi dengan Warga Batang" tayang pada 19 Juni 2014.

\section{Gambar 4. Potongan Berita Pemilu Presiden 2014}

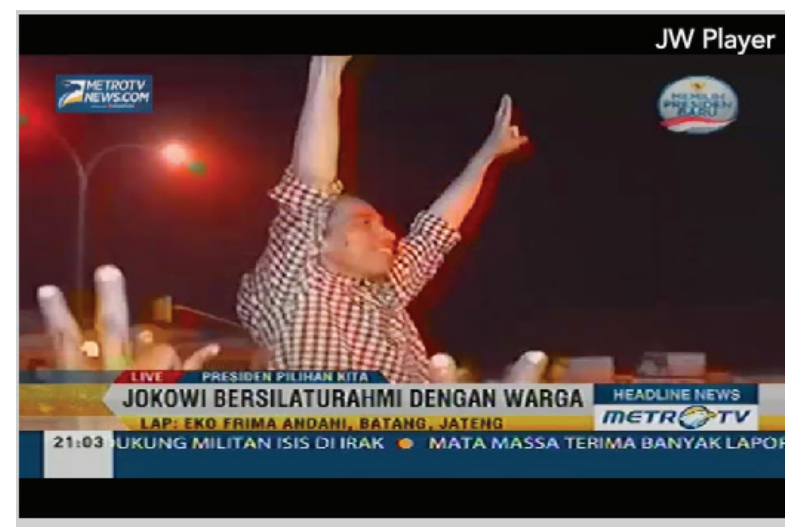

Sumber : Metro TV

Dengan narasi :

Headline News, Kamis (19/6/2014): Calon Presiden Nomor Urut 2 Joko Widodo bersilaturahmi dengan warga Batang, Jawa Tengah, Kamis malam. Karena warga memadati jalan, rombongan Jokowi berjalan kaki menuju alun-alun. Sebelumnya Jokowi menyempatkan dirinya ke Pasar Induk Kajen Pekalongan.

Personalisasi oleh media inilahyang digunakan dalam konteks penelitian ini. Berdasarkan pemahaman diatas, kemudian disusun seperangkat indikator yang masuk dalam kategori personalisasi, antara lain: Pertarungan antar kandidat, Aktivitas kampanye kandidat, Aktivitas personal kandidat, Profil pribadi kandidat, Tanggapan individu atas isu yang menimpa dirinya (tanggapan personal). Lozano (2004:6)

\section{Sensasionalisme}

Kemudian yang muncul dari tabloidisasi adalah beritayang sensasionalisme. Sensasionalisme biasanya digunakan dalam pengertian yang luas. Ditinjau dari objektivitas berita, maka sensasionalisme adalah elemen yang potensial dalam mengurangi kenetralan dan keberimbangan. Tetapi, ditinjau dari perspektif hiburan, sensasionalisme adalah segala bentuk ciptaan yang direkayasa agar mampu membangkitkan sensasi. Dalam telaan objektivitas berita, sensasionalisme biasanya menjadi konsep yang berdiri sendiri. Pemahaman paling jelas mengenai sensasionalisme dilihat dari objektivitas berita, bisa didapat melalui 3 dimensi sensasionalisme McQuail (1992: 233), yaitu dramatisasi, emosionalisasi, dan personalisasi.

Dalam berita di Headline news Metro TV juga menampilkan berita yang sensasional, seperti dalam judul "Silaturahmi Di Purwakarta, Jokowi: Jangan Percaya Fitnah dan Hasutan!"yang tayang pada 17 Juni 2014.

Gambar 5. Potongan Berita Pemilu Presiden 2014

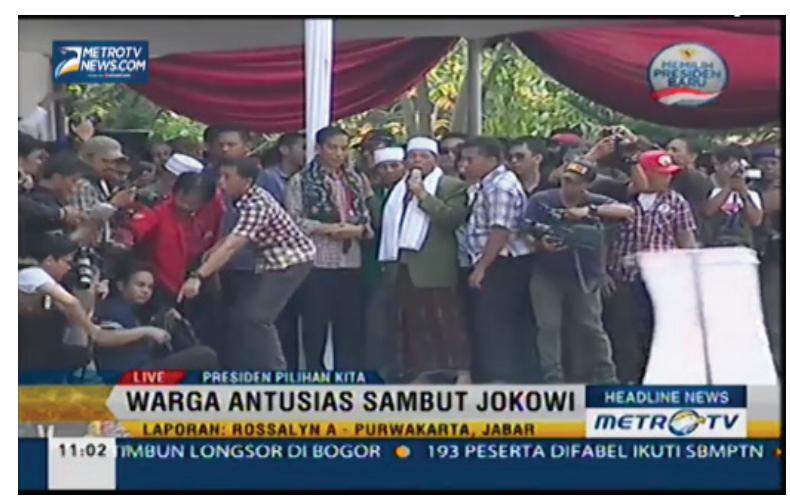

Sumber : Metro TV

Dengan narasi :

Headline News, Selasa (17/6/2014): Calon Presiden Joko Widodo menyambangi warga Purwakarta, Jawa Barat. Dalam pidato politiknya Jokowi membantah isu negatifyang menimpa dirinya di depan ribuan masyarakat Purwakarta.

Pada dasarnya dimensi ini melihat pada penggunaan gaya bahasa. Bahwa pilihan kata yang dihadirkan oleh media itu menunjukkan adanyaketidak-objektiv-an atau keberpihakan. Dramatisasi misalnya, ia dilihat daripenggunaan kata (majas) hiperbola. Dalam berita ini memang penulis tidak bisa mentranskrip seluruh narasi yang ada, sehingga kurang bisa mengamati secara detail. Kemudian, dimensi kedua: emosionalisasi. Dimensi ini melihat bahwa pemilihan kata didasarkan pada aspek 
emosi (senang, sedih, marah, dll) ketimbang rasio, sehingga bisamengurangi netralitas. Dalam berita di Headline News Metro TV ini terlihat penggunaan tanda seru dalam penulisan judulnya, maka sisi emosi sengaja ditonjolkan. Ketiga, personalisasi, yang berarti penggunaan gaya bahasa yang menonjolkan seseorang menjadi tokoh sentral dalam pembahasan. Jelas bahwa dalam berita ini Jokowi menjadi tokoh sentral dalam pemberitaannya.

\section{Trivialisasi}

Kemudian salah satu elemen kuat tabloidisasi ditinjau dari konversinya terhadap "trash taste" adalah ketika berita televisi mulai sering mengetengahkan sisisisi 'lain' dalam berita. Sisi 'lain' ini bisa berupa pernak-pernik atau atribut trivial yang meskipun nyata, tetapi sebetulnya tidak penting untuk disampaikan. Berita televisi melakukan tabloidisasi saat atribut yang tidak penting tersebut dicampurkan dalam narasi. Mengukur trivialisasi dalam berita televisi ini bisa dikatakan paling sulit dibandingkan mengukur elemen yang lain, karena tidak ada referensi dari penelitian empirik.Trivialisasi bisa dilihat dari adanya berita yang memuat : Atribut Fisik, Selera individu, Suasana lingkungan, Pembelokan isu, dan Aktivitas emosional (Nusantari,2013:58).

Konsep Trivialisasi ini juga ditunjukkan dalam program Headline News Metro TV, yang berjudul "Ratusan Perempuan se Bogor Raya Kumpulkan Sendok Dukung Jokowi-JK" yang tayang pada 16 Juni 2014.

Gambar 6. Potongan Berita Pemilu Presiden 2014

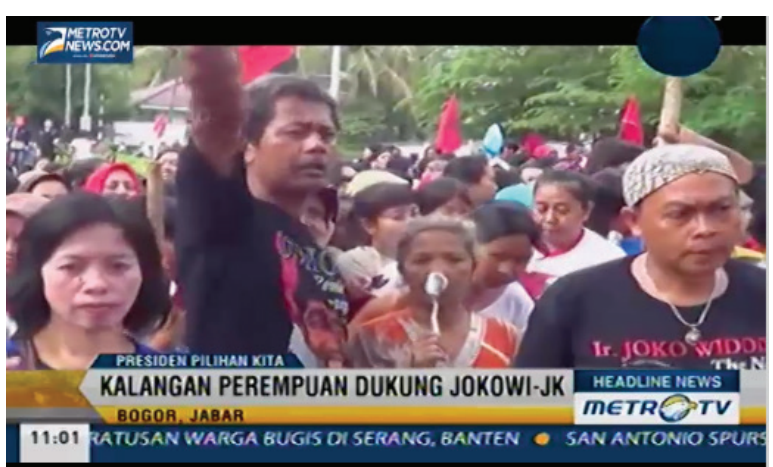

Sumber : Metro TV
Dengan Narasi :

Headline News, Senin (16/06/2014): Dukungan terhadap pasangan Capres-Cawapres JokowiAhok datang dari ratusan perempuan se wilayah Bogor Raya. Uniknya dukungan ini dilakukan dengan mengumpulkan sendok makan yang nantinya akan diberikan kepada pasangan Jokowi-JK sebagai simbol dukungan ketahanan pangan nasional.

Sisi 'lain' dari konsep trivialisasi yakni berupa pernak-pernik atau atribut trivial yang meskipun nyata, tetapi sebetulnya tidak penting untuk disampaikanPada berita ini memuat atribut yang sebenarnya tidak relevan dengan topic utama, yakni diperlihatkan dengan adanya aktivitas emosional dari selebrasi simpatisan yang mengumpulkan sendok makan yang nantinya akan diberikan kepada pasangan Capres dan Cawapres yang akan mereka dukung. Aktivitas pengumpulan sendok ini sebenarnya tidak terlalu penting untuk disampaikan. Namun inilah yang terjadi, tabloidisasi memberikan keleluasaan dalam membuat berita seperti ini.

\section{Pers Populer di Media Televisi}

Pola tabloidisasi ini muncul akibat persaingan industri media yang ketat. Televisi menjadi media yang lebih rentan tergerus tabloidisasi. Karena medium televisi mampu menerjemahkan semua tema diskursus ke dalam format menghibur, bahkan untuk berbagai persoalan yang memerlukan diskusi dan pembahasan mendalam seperti diskursus politik, keagamaan dan ilmu pengetahuan disajikan dalam format hiburan (Postman, 1995).

Pers populer dibangun dengan logika yang berkebalikan dengan quality press. Pers ini memiliki ciri pemberitaan yang dengan sengaja disampaikan secara provokatif atau dimanipulasi untuk "memukau" atau menarik perhatian pemirsa. Produk-produk yang dikategorikan "pers populer" biasa mengambil pendekatan seperti tabloid. Jurnalisme jenis ini konsepnya adalah otentik, namun padaperkembangannya memanipulasi konsep dan kemasannya sehingga bergaya hiburan dan meninggalkan nilai-nilai murni jurnalistik. Jurnalisme 
ini lebih mengutamakan tingkat menariktidaknya berita dibanding isi dan informasi analisis itu sendiri (Harcup 2004: 90).

Hadirnya tabloidisasi kemudian membuat batas-batas antara quality press dengan popular press menjadi cair. Beberapa pandangan menyatakan bahwa tabloidisasi tidak selamanya buruk karena merupakan suatu bentuk demokratisasi dalam produksi media (TrampotaKoncelik, 2011: 289). Selain itu, mekanisme tabloidisasi terbukti mampu memberikan profit bagi industri media.

Pada media televisi, berita merupakan sumber informasi yang paling banyak diakses dan dipercaya oleh masyarakat. Khususnya Metro TV yang menjadi referen channel berita di Indonesia. Hal ini bisa dipahami mengingat televisi relatif murah dan memiliki kekuatan audiovisual. Sehingga menyaksikan televisi seolah melihat sendiri suatu peristiwa.Pada mekanisme pasar, daya tarik ini kemudian membuat televise senantiasa tergerak untuk menampilkan berita yang bisa mendatangkan banyak penonton. Sehingga, akan ada banyak iklan dan semakin untung pula pembuatnya. Padahal, pesan ini juga berfungsi secara sosial. Bagi para audiens, pesan yangdibawa oleh berita televisi juga digunakan untuk menambah pengetahuan dalam memahami realitas sosial.

\section{Penutup}

Tabloidisasi memiliki prinsip yang bertentangan dengan quality journalism memiliki nilai ideal berupa pelayanan kepada publik, etika, dan kedalaman. Sementara itu, tabloidisme mencari segala sesuatu untuk memenuhi kesenangan pribadi. Dalam konteks pemilihan umum, penerapan quality journalism lebih menguntungkan bagi publik, karena warga sebagai voter (pemilih) memerlukan informasi yang substansial dalam rangka menentukan pilihan.

Gambaran mengenai tabloidisasi ini bisa dijelaskan dengan melihat proporsi yang termasuk unsur tabloidisme, yakni dalam tulisan ini penulis menggunakan 3 unsur (Personalisasi, Sensasionalisme, Trivialisasi). Personalisasi yang ditunjukkan dengan orientasi pemilihan topik berita yang lebih bernilai personal dibandingkan publik. Tingginya personalisasi ini menunjukkan bahwa tabloidisasi terjadi secara substansial. Dalam hal ini Metro TV melalui program Headline News menyajikan berita pemilihan umum presiden 2014 sebagai ajang persaingan antar kandidat dan mengarahkan pemberitaannya untuk meliput aktivitas personal dan aktivitas kampanye.

Keterkaitan antara opini dan fakta menjadi tanda bahwa sensasionalisme juga tersaji dalam berita di Headline News Metro TV. Berita-berita yang ada seringkali dibawakan dalam keadaan sangat cair, artinya memiliki ciri pemberitaan yang dengan sengaja disampaikan secara provokatif atau dimanipulasi untuk "memukau" atau menarik perhatian pemirsa dan berkenalikan dengan quality pers.

Yang terakhir adalah Trivialisasi, adanya trivialisasi ini juga menandakan adanya tabloidisasi dalam Headline News Metro TV. Dengan menyajikan data-data yang unik namun tidak memiliki relevansinya dengan pemilihan umum presiden 2014.

\section{Daftar Pustaka}

Harcup, Tony. 2009. Journalism Principles and Practice Second Edition. London: Sage Publications

Harrington, Sephen. 2008. Popular News in The Twenty-First Century: Time For A New Critical Approach? Journalism: Theory, Practice, and Criticism, Vol 9, 266-284

Lozano, Jose C. 2004. Infotainment in National TV News: A Comparative Content Analysis of Mexican, Canadian, and U.S. News Programs. Paper presented at the Annual Conference of the International Association for Media and Communication Research. Porto Alegre, Brasil

Lehman-Wilzig, Sam \& Seletzky, Michael. 2012. Elite and Popular Newspaper Publication of Press Releases: Differential Success Factors? Public Relations Journal, Vol. 6, No. 1, 1-25 
Mooney, Attracta M. 2008. Tabloidization and The Irish Press Media. MA Theses. International Journalism Research, University of Leeds

McQuail, Denis. 1992. Media Performance: Mass Communication and The Public Interest, London, Sage Publication.

Nusantari, Adinda.2013.Tabloidisasi Dalam Pemberitaan Televisi (Analisis Isi Terhadap Berita Pemilihan Gubernur DKI Jakarta pada Program Metro Hari Ini dan Kabar Petang Juni-September 2012).Tesis.Yogyakarta: Universitas Gadjah Mada

Sparks, Colin \& Tulloch, John (Eds). 2000. Tabloid Tales: Global Debates Over Media Standards. New York: Rowman \& Littlefield Publishers, Inc

Postman, Neil. 1995. Menghibur Diri Sampai Mati: Mewaspadai Media Televisi. Jakarta: Pustaka Sinar Harapan
Trampota, Tomas \& Koncelik, Jakub. 2011. The Tabloidisation of The Czech Daily Press. Boguslawa Dobek-Ostrowska \& Michal Glowacki (Editors). Making Democracy in 20 years: Media and Politics in Central and Eastern Europe. Wroclaw: Wydawnictvo Uniwesytetu Wroclawskiego, hal. 287-298

Zoonen, Liesbet van dan Rosa van Santen. 2011. Personalization: A Theoritical and Historical Account. Paper Presented atECPR General Conference 2011. Reykjavik, Iceland

http://news.metrotvnews.com/video, diakses pada 28 Oktober 2014 pukul 13.40 WIB 